\title{
MODELING MORPHOLOGICAL EVOLUTION IN THE VICINITY OF COASTAL STRUCTURES
}

\author{
Pham Thanh Nam¹ ${ }^{1}$ Magnus Larson ${ }^{2}$, and Hans Hanson ${ }^{3}$
}

\begin{abstract}
A numerical model of beach topography evolution was developed. The model includes five sub-models: random wave transformation model, surface roller model, wave-induced current model, sediment transport model, and morphological change model. The model was validated by two unique high-quality data sets obtained from experiments on the morphological impact of a detached breakwater and a T-head groin in the basin of the Large-scale Sediment Transport Facility (LSTF) at the US Army Corps of Engineer Research and Development Center in Vicksburg, Miss. The simulations demonstrated that the model well reproduced the wave conditions, wave-induced currents, and morphological evolution in the vicinity of the structures.
\end{abstract}

Keywords: morphodynamics; random waves; wave-induced currents; sediment transport; breakwater; T-head groin

\section{INTRODUCTION}

Coastal structures, such as groins and detached breakwaters, are frequently utilized in coastal engineering projects to prevent beach erosion. Thus, understanding the morphological evolution in the vicinity of coastal structure is necessary to achieve an optimal functional design. There have been many attempts to develop numerical models for simulating beach topography change around structures (Nicholson et al., 1997; Leont'yev, 1999; Zyserman and Johnson, 2002; Johnson, 2004; Saied and Tsanis, 2005). However, the hydrodynamics and sediment transport processes are highly complex in the vicinity of coastal structures. Moreover, the validation of numerical models against high-quality data sets is still limited. Thus, the development of models that accurately predict the morphological evolution around structures remains a challenge.

The aim of this study is to develop a robust and reliable numerical model to simulate beach topography evolution due to waves and currents with the emphasis on the impact of coastal structures. In order to do this, the wave model developed by Mase (2001) was employed for calculating the multidirectional and frequency random wave transformation, in which the energy dissipation term in the energy balance equation was modified after Dally et al. (1985) to obtain better agreement with measurements of the wave height in the surf zone. The surface roller itself was determined based on the work of Dally and Brown (1995) and Larson and Kraus (2002). The roller energy flux term in the alongshore direction was included in the energy balance equation. The nearshore wave-induced currents and wave setup were derived from the momentum equations and the continuity equation, where the wave stresses were derived from the wave and roller models. The sediment transport rates in the swash zone were calculated based on the model by Larson and Wamsley (2007). In the offshore and surf zone, the bed load was determined by the unified formula of Camenen and Larson (2005, 2007), whereas the suspended load was derived based on the advection-diffusion equation. The morphological evolution due to waves and currents was calculated based on the sediment mass conservation equation.

The developed model was tested against two detailed, high-quality data sets including a detached breakwater and a T-head groin. The data were collected at the Large-scale Sediment Transport Facility (LSTF) basin at the Coastal and Hydraulics Laboratory (CHL) in Vicksburg (Gravens et al., 2006; Gravens and Wang, 2007). The model produced good agreement concerning wave conditions, waveinduced currents, sediment transport, and morphological evolution around the detached breakwater and the T-head groin.

\section{MODEL DESCRIPTION}

\section{Wave model}

In this study, we employed a multidirectional random wave transformation model that based on the energy balance equation with diffraction and dissipation terms (Nam et al., 2009; Nam and Larson, 2009, 2010). The original wave model (EBED) was developed by Mase (2001). We have modified the

\footnotetext{
${ }^{1}$ Dept. of Water Resources Engineering, Lund University, Box 118, 22100 Lund, Sweden.

thanh_nam.pham@tvrl.Ith.se

2 Ditto. magnus.larson@tvrl.Ith.se

${ }^{3}$ Ditto. hans.hanson@tvrl.Ith.se
} 
energy dissipation term based on the study of Dally et al. (1985) in order to improve the predictive capability of the wave model in the surf zone. The modified energy balance equation proposed is as follows:

$$
\frac{\partial\left(v_{x} S\right)}{\partial x}+\frac{\partial\left(v_{y} S\right)}{\partial y}+\frac{\partial\left(v_{\theta} S\right)}{\partial \theta}=\frac{\kappa}{2 \omega}\left\{\left(C C_{g} \cos ^{2} \theta S_{y}\right)_{y}-\frac{1}{2} C C_{g} \cos ^{2} \theta S_{y y}\right\}-\frac{K}{h} C_{g}\left(S-S_{s t a b}\right)
$$

where $S$ the angle-frequency spectrum density, $(x, y)$ the horizontal coordinates, $\left(v_{x}, v_{y}, v_{\theta}\right)$ the propagation velocities in their respective coordinate direction, $\theta$ the angle measured counterclockwise from the $x$ axis, $\omega$ the frequency, $C$ the phase speed, $C_{g}$ the group speed, $\kappa$ the free parameter that can be optimized to change the influence of the diffraction effects, $h$ the still-water depth, $K$ the dimensionless decay coefficient, and $S_{\text {stab }}$ the stable wave spectrum density, which is a function of the stable wave height $H_{\text {stab }}(=\Gamma \mathrm{h})$, with $\Gamma$ being a dimensionless empirical coefficient. Based on the work by Goda (2006) model, the coefficients $K$ and $\Gamma$ can be determined as,

$$
\begin{cases}\Gamma=0.45, K=\frac{3}{8}(0.3-19.2 s) & : s<0 \\ \Gamma=0.45+1.5 s, K=\frac{3}{8}(0.3-0.5 s) & : 0 \leq s \leq 0.6\end{cases}
$$

where $s$ is the bottom slope.

The model is referred to as the Modified-EBED model hereafter. The output of the model includes three main parameters: significant wave height $H_{s}$, significant wave period $T_{s}$, and mean wave direction $\bar{\theta}$. The wave stresses can be determined based on the output of the wave model as,

$$
S_{x x}=\frac{E}{2}\left[2 n\left(1+\cos ^{2} \bar{\theta}\right)-1\right] ; S_{y y}=\frac{E}{2}\left[2 n\left(1+\sin ^{2} \bar{\theta}\right)-1\right] ; S_{x y}=\frac{E}{2} n \sin 2 \bar{\theta}
$$

where $E=\rho g H_{r m s}^{2} / 8$ is the wave energy per unit area, and $\rho$ the water density, $g$ the acceleration due to gravity, and $n=C_{g} / C$ the wave index.

\section{Surface roller model}

The energy balance equation for the surface roller in two dimensions is expressed as (Dally and Brown, 1995; Larson and Kraus 2002):

$$
P_{D}+\frac{\partial}{\partial x}\left(\frac{1}{2} M C_{r}^{2} \cos ^{2} \bar{\theta}\right)+\frac{\partial}{\partial y}\left(\frac{1}{2} M C_{r}^{2} \sin ^{2} \bar{\theta}\right)=g \beta_{D} M
$$

where $P_{D}$ is the wave energy dissipation $\left(=K C_{g} \rho g\left(H_{r m s}^{2}-(\Gamma h)^{2}\right) /(8 h)\right), M$ the period-averaged mass flux, $C_{r}$ the roller speed ( $\approx C$ ), and $\beta_{D}$ the roller dissipation coefficient.

The stresses due to the rollers are determined by the following formulas:

$$
R_{x x}=M C_{r} \cos ^{2} \bar{\theta} ; R_{y y}=M C_{r} \sin ^{2} \bar{\theta} ; R_{x y}=M C_{r} \sin 2 \bar{\theta}
$$

\section{Nearshore wave-induced current model}

The governing equations for the nearshore currents are written as (Militello et al., 2004),

$$
\begin{aligned}
& \frac{\partial(h+\eta)}{\partial t}+\frac{\partial q_{x}}{\partial x}+\frac{\partial q_{y}}{\partial y}=0 \\
& \frac{\partial q_{x}}{\partial t}+\frac{\partial u q_{x}}{\partial x}+\frac{\partial v q_{x}}{\partial y}+g(h+\eta) \frac{\partial \eta}{\partial x}=\frac{\partial}{\partial x} D_{x} \frac{\partial q_{x}}{\partial x}+\frac{\partial}{\partial y} D_{y} \frac{\partial q_{x}}{\partial y}+f q_{y}-\tau_{b x}+\tau_{S x} \\
& \frac{\partial q_{y}}{\partial t}+\frac{\partial u q_{y}}{\partial x}+\frac{\partial v q_{y}}{\partial y}+g(h+\eta) \frac{\partial \eta}{\partial y}=\frac{\partial}{\partial x} D_{x} \frac{\partial q_{y}}{\partial x}+\frac{\partial}{\partial y} D_{y} \frac{\partial q_{y}}{\partial y}-f q_{x}-\tau_{b y}+\tau_{S y}
\end{aligned}
$$

where $\eta$ is the water level, $\left(q_{x}, q_{y}\right)$ the flow per unit width in $\mathrm{x}$ and $\mathrm{y}$ direction, respectively, $(u, v)$ the depth-averaged velocity, $\left(D_{x}, D_{y}\right)$ the eddy viscosity coefficients, $f$ the Coriolis parameter, $\left(\tau_{b x}, \tau_{b y}\right)$ the bottom stresses, and $\left(\tau_{S x}, \tau_{S y}\right)$ the wave stresses.

The eddy viscosity in the offshore can be calculated from Falconer (1980), whereas it can be determined following Kraus and Larson (1991) for the surf zone. The bottom stresses can be calculated 
from Nishimura (1988). The wave stresses were derived by the Modified-EBED model and the surface roller model.

\section{Sediment transport model}

In the swash zone, the net transport rates in the cross-shore and longshore directions, respectively, were determined based on the formulas of Larson and Wamsley (2007) as,

$$
\begin{aligned}
& q_{b c, n e t}=K_{c} \frac{\tan \phi_{m}}{\tan ^{2} \phi_{m}-(d h / d x)^{2}} \frac{u_{0}^{3}}{g}\left(\frac{d h}{d x}-\tan \beta_{e}\right) \frac{t_{0}}{T} \\
& q_{b l, n e t}=K_{l} \frac{\tan \phi_{m}}{\tan ^{2} \phi_{m}-(d h / d x)^{2}} \frac{u_{0}^{2} v_{0}}{g} \frac{t_{0}}{T}
\end{aligned}
$$

where $q_{b c, \text { net }}, q_{b l, \text { net }}$ are the net transport in the cross-shore and longshore directions, respectively, $K_{c}$ and $K_{l}$ empirical coefficients, $\phi_{m}$ the friction angle for a moving grain $(\approx 30 \mathrm{deg}), \beta_{e}$ the foreshore equilibrium slope, $u_{0}, v_{0}$ and $t_{0}$ the scaling velocities and time, respectively, and $T$ the swash duration (assumed that $T$ is equal to the incident wave period). The swash zone hydrodynamics without friction, which were derived based on the ballistic theory, were employed in the model (for details see Larson and Wamsley, 2007).

In the offshore and surf zone, the bedload can be calculated by the formula of Camenen and Larson $(2005,2007)$ as,

$$
\frac{q_{b c}}{\sqrt{(s-1) g d_{50}^{3}}}=a_{c} \sqrt{\theta_{c}} \theta_{c w, m} \exp \left(-b_{c} \frac{\theta_{c r}}{\theta_{c w}}\right)
$$

where the transport $q_{b c}$ is obtained in the direction of the current (the transport normal to the current is taken to be zero), $s$ the relative density between sediment and water, $d_{50}$ the median grain size, $a_{c}$ and $b_{c}$ empirical coefficients, $\theta_{c w, m}$ and $\theta_{c w}$ the mean and maximum Shields parameters due to wave and current interaction, respectively, $\theta_{c r}$ the critical Shields parameter, and $\theta_{c}$ the Shields parameter due to current.

The suspended load in the surf zone and offshore zone can be derived from the advectiondiffusion equation:

$$
\frac{\partial(\bar{C} d)}{\partial t}+\frac{\partial\left(\bar{C} q_{x}\right)}{\partial x}+\frac{\partial\left(\bar{C} q_{y}\right)}{\partial y}=\frac{\partial}{\partial x}\left(K_{x} d \frac{\partial \bar{C}}{\partial x}\right)+\frac{\partial}{\partial x}\left(K_{y} d \frac{\partial \bar{C}}{\partial y}\right)+\bar{P}-\bar{D}
$$

where $\bar{C}$ is the depth-averaged sediment concentration, $K_{x}$ and $K_{y}$ the sediment diffusion coefficient in $x$ and $y$ direction, respectively, $\bar{P}$ the sediment pick-up rate, and $\bar{D}$ the sediment deposition rate (for details see Nam et al., 2009).

\section{Morphological model}

The beach morphological evolution under waves and currents was determined based on the sediment mass conservation equation.

$$
\frac{\partial h}{\partial t}=\frac{1}{1-n_{p}}\left(\frac{\partial q_{t o t, x}}{\partial x}+\frac{\partial q_{t o t, y}}{\partial y}\right)
$$

where $n_{p}$ is porosity parameter, and $q_{t o t, x}$ and $q_{t o t, y}$ the total load in $x$ and $y$ directions, respectively. In the swash zone, the total load is based on the net transport rates obtained by (9) and (10). In the offshore and surf zone, it is the sum of bed load and suspended load, which are calculated based on equations (11) and (12).

\section{LSTF DATA}

Five series of physical model experiments were carried out in the LSTF basin at CHL (Gravens et al., 2006; Gravens and Wang, 2007). The main objective of these experiments was to obtain highquality data sets for validating sediment transport relationships, as well as investigating the morphological evolution in response to coastal structures such as detached breakwater and T-head groin. The sand with median grain size of $0.15 \mathrm{~mm}$ was used to create the sandy beach inside the LSTF 
basin. Spilling breaking waves were generated by four wave-generators, and the water was recirculated by pumping systems located at up and downstream of the basin. The instrument bridge, that carried the wave and current sensors, were moved in the alongshore direction; therefore, the wave conditions and currents could be observed at specific cross-shore profiles. The wave and current sensors were co-located at ten locations on the bridge: $1.125 \mathrm{~m}$ (ADV1), $2.2 \mathrm{~m}$ (ADV2), $3.3 \mathrm{~m}$ (ADV3), $4.125 \mathrm{~m}$ (ADV4), $5.73 \mathrm{~m}$ (ADV5), $7.125 \mathrm{~m}$ (ADV6), $8.525 \mathrm{~m}$ (ADV7), $10.125 \mathrm{~m}$ (ADV8), $11.625 \mathrm{~m}$ (ADV9), and $13.125 \mathrm{~m}$ (ADV10) seaward from the initial still water shoreline. After each run of the experiments, beach profiles were measured by rod and acoustic survey techniques.

In this study, we employed two data sets from the LSTF experiments obtained from one run with a detached breakwater (Test T1C1) and one run with a T-head groin (Test T3C1). The layouts of two tests are presented in Fig. 1 and Fig. 2, respectively. The initial shorelines for both runs were straight and their beach topographies were quite uniform in alongshore direction. The wave conditions and currents were measured at thirteen cross-shore profiles from profile Y34 to profile Y14. Three gages (\#11, \#12, and \#13) were located at three positions, a distance $18.43 \mathrm{~m}$ seaward from the initial still water shoreline, to measure the wave conditions seaward of the toe of the movable beach.

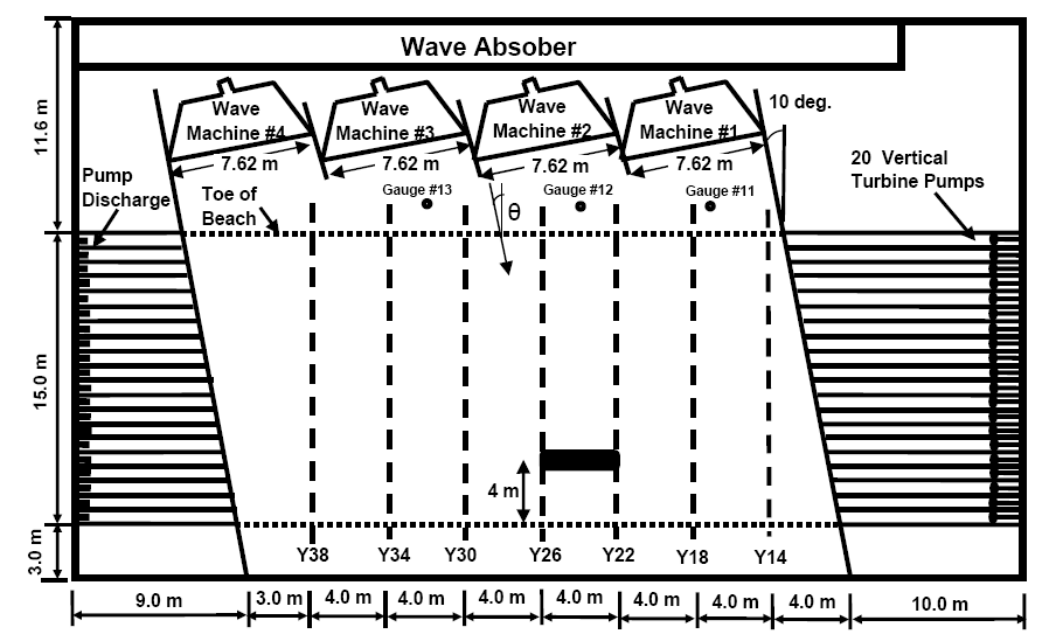

Fig. 1. Detached breakwater layout in LSTF basin for Test T1C1 (Gravens and Wang, 2007)

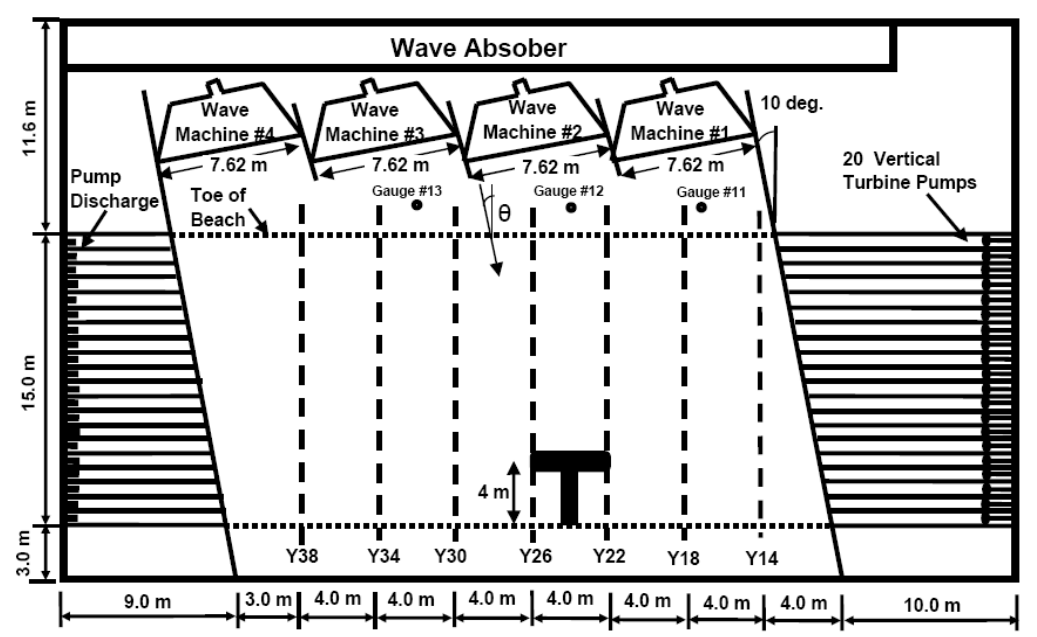

Fig. 2. T-head groin layout in LSTF basin for Test T3C1 (Gravens and Wang, 2007)

\section{VALIDATION OF NUMERICAL MODEL AGAINST LSTF DATA}

\section{Model input}

The model grid is rectangular with the cell size $0.2 \times 0.2 \mathrm{~m}$ which is generated based on the bathymetry data from profile Y34 to profile Y14. The wave conditions measured at three gages \#11, $\# 12$, and \#13 were used as the offshore wave conditions (for details, see Table 1). The wave spectrum 
density at the offshore boundary was represented by a TMA spectrum with the parameter values $\gamma=3.3$, $\sigma_{a}=0.07, \sigma_{b}=0.09$, and the wave angular spreading $S_{\max }=25$. The decay and stable wave height coefficient were determined from Eq. (2), and the roller dissipation coefficient was set to $\beta_{D}=0.1$. A Manning coefficient of 0.025 was employed to determine the bottom friction. The measured velocities at profile Y34 and Y14 were used to specify the influx and outflux of water at the lateral boundaries for the nearshore current model. At the offshore boundary, a radiation boundary condition was employed (Reid and Bodine, 1968). The values of $K_{c}$ and $K_{l}$ were both set to 0.0008 for calculating the net transport rates in the swash zone. The coefficient values $a_{c}$ and $b_{c}$ in the bedload formula were given as 12 and 4.5, respectively. The diffusion coefficients in the Eq. (12) were calculated based on the study of Elder (1959). The porosity parameter in the mass conservation equation was given as 0.4 .

\begin{tabular}{|c|c|c|c|c|c|c|}
\hline \multicolumn{7}{|c|}{ Table 1. Offshore conditions for T1C1 and T3C1 } \\
\hline \multirow{2}{*}{ Gages } & \multicolumn{3}{|c|}{ Test case T1C1 } & \multicolumn{3}{c|}{ Test case T3C1 } \\
\cline { 2 - 7 } & $\mathrm{H}_{\mathrm{mo}}(\mathrm{m})$ & $\mathrm{T}_{\mathrm{p}}(\mathrm{s})$ & $\theta$ (deg.) & $\mathrm{H}_{\mathrm{mo}}(\mathrm{m})$ & $\mathrm{T}_{\mathrm{p}}(\mathrm{s})$ & $\theta$ (deg.) \\
\hline$\# 11$ & 0.219 & 1.442 & 6.5 & 0.218 & 1.447 & 6.5 \\
$\# 12$ & 0.236 & 1.470 & 6.5 & 0.231 & 1.477 & 6.5 \\
$\# 13$ & 0.226 & 1.459 & 6.5 & 0.223 & 1.450 & 6.5 \\
\hline
\end{tabular}

\section{Detached breakwater test T1C1}

Fig. 3 shows the comparison between the measurements and calculations of significant wave height along six selected cross-shore profiles in the vicinity of detached breakwater. The blue solid line is the calculation obtained by the Modified-EBED model, whereas the red dashed line is calculation by the original EBED model. As can be seen, the EBED model produced overestimation of significant wave height in the surf zone. Using the Modified-EBED model, the agreement with the measurements was significantly improved. Thus, the Modified-EBED model can provide more accurate wave stresses for calculating the nearshore wave-induced currents.
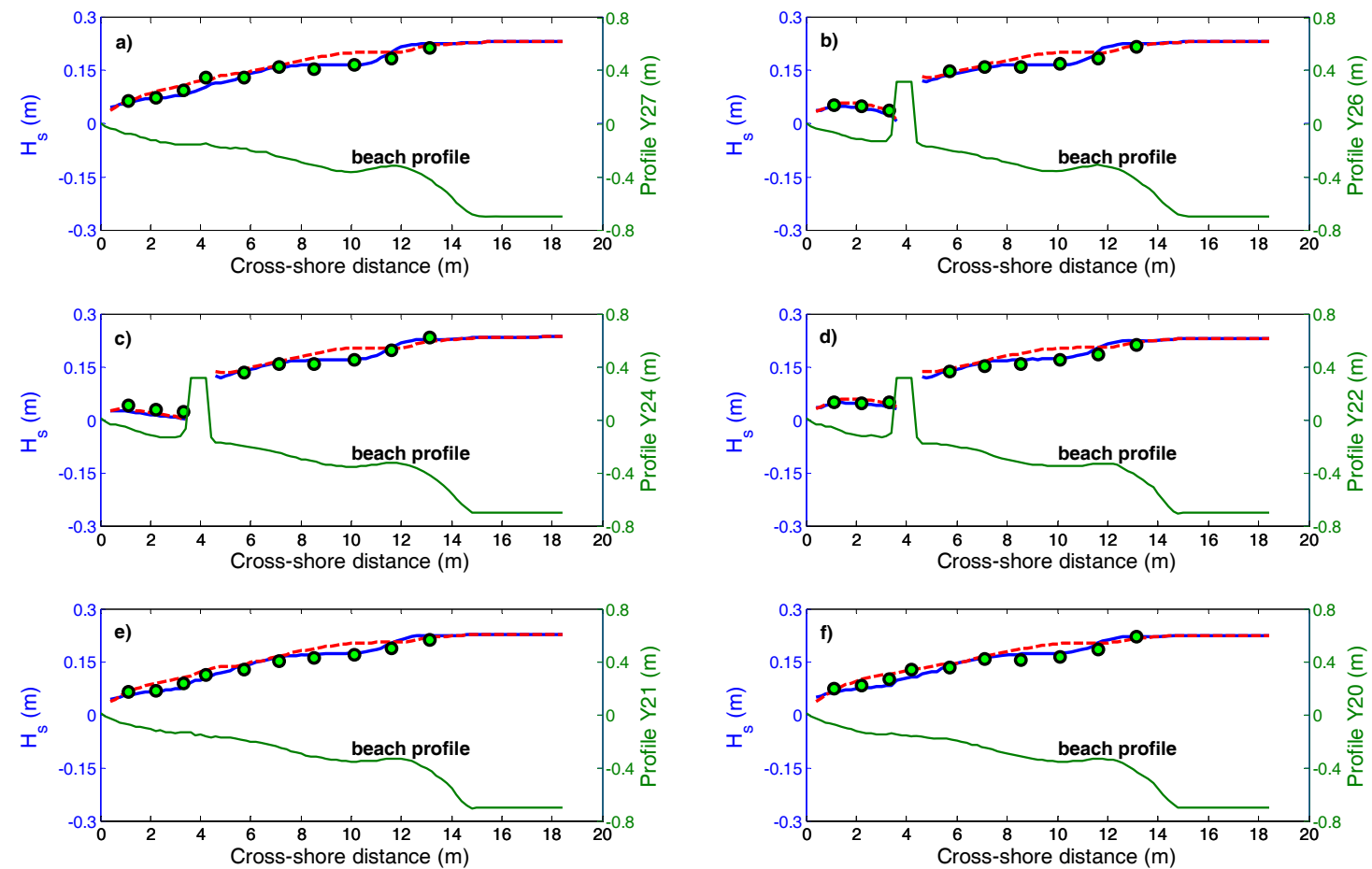

- Modified-EBED -----EBED 0 Measured

Fig. 3. Comparison between measured and calculated significant wave height for LSTF case T1C1

The comparisons between the calculated longshore current and cross-shore current, and the observed data are presented in Fig. 4 and 5, respectively. The calculations showed that both longshore 
currents with roller 2D and without roller were in good agreement with measurements. By including the roller effects, the peak of longshore current was shifted toward the shoreline and the magnitude of the current was slightly increased in the surf zone.
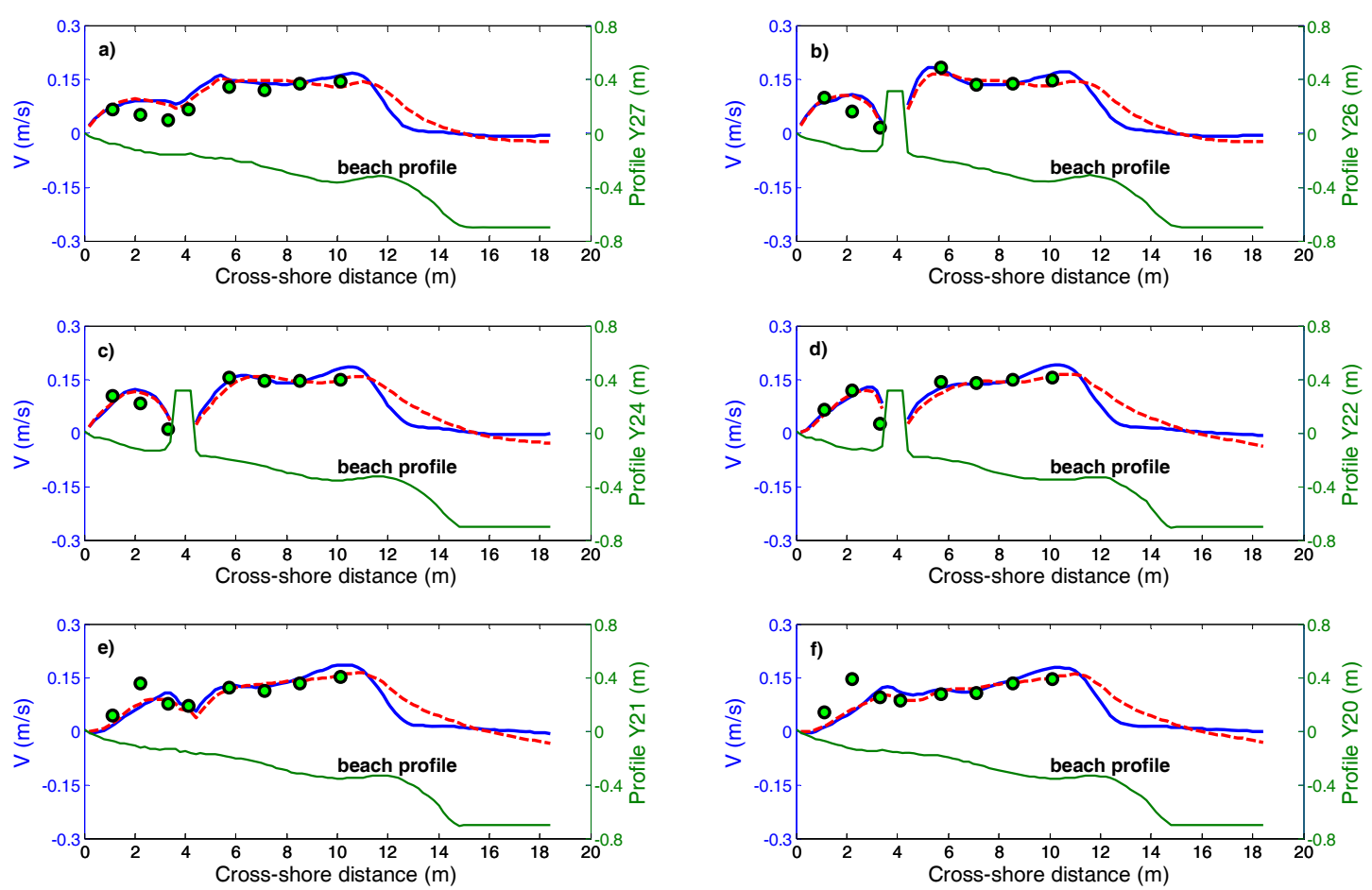

- With roller 2D ---- Without roller 0 Measured

Fig. 4. Comparison between measured and calculated longshore current for LSTF case T1C1
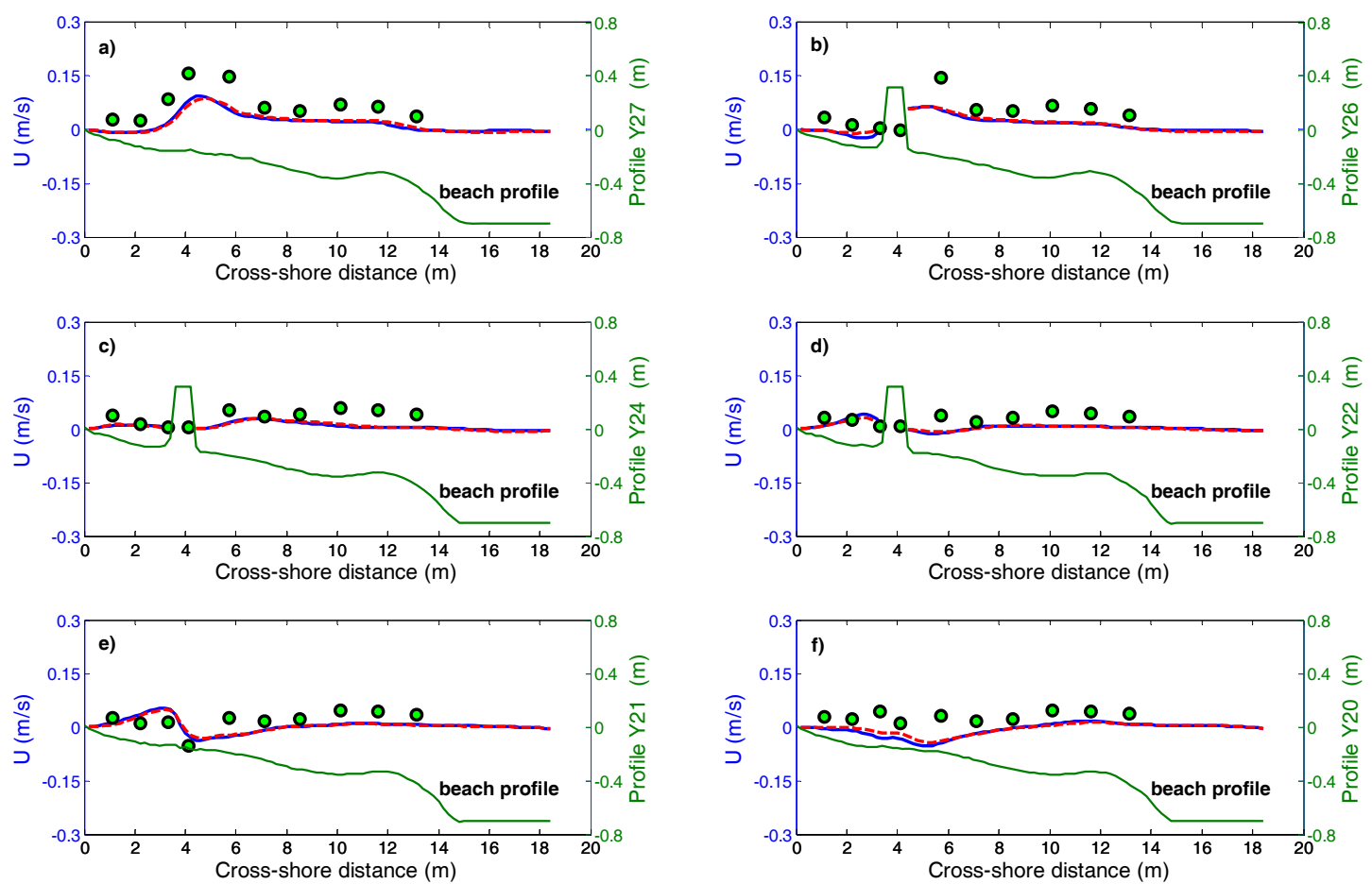

- With roller 2D ---. Without roller $\circ$ Measured

Fig. 5. Comparison between measured and calculated cross-shore current for LSTF case T1C1 
The differences between the calculations of cross-shore current with roller $2 \mathrm{D}$ and the one without roller were relatively small. The calculated cross-shore current was somewhat underestimated compared to the measurements, although it was in rather good agreement with observed data in the lee of detached breakwater. An eddy was generated around the ADV3 - ADV6 in profile Y20. Thus, the calculated cross-shore current had a shoreward direction which was different from the measurements (see Fig. 5f). In this study, the undertow was not included in the model, which is probably the main reason for the discrepancy between calculations and measurements of cross-shore current.

The comparison between the calculated bed level after $185 \mathrm{~min}$ and the measurements is displayed in Fig. 6. The solid line shows the calculation of bed level, whereas the dotted line shows the measurements. The simulation showed that the calculated beach evolution in the vicinity of the detached breakwater agreed well with the measurements, especially the salient that developed in the lee of the detached breakwater. However, the calculated shoreline change downstream was different from the measurements. The observed data indicated that the shoreline eroded here, but this erosion was not well reproduced by the numerical model. The impacts of the pumping system on the movement of sediment at the downstream end were not accounted for, possibly causing the difference between the measurements and calculations.

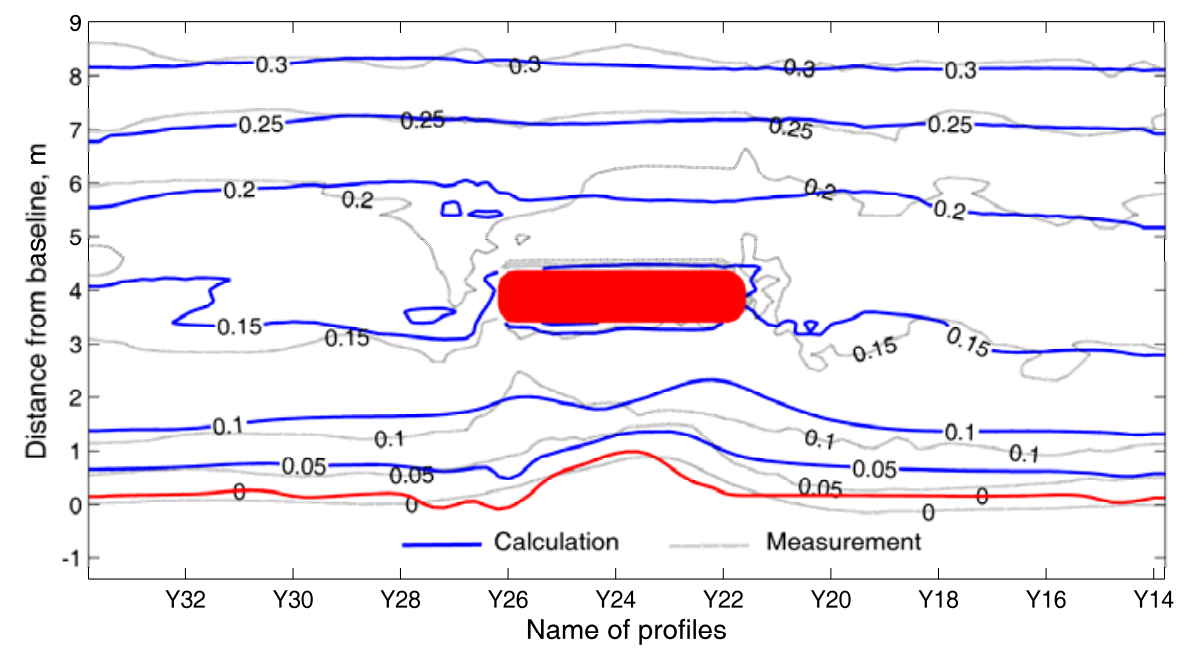

Fig. 6. Comparison between calculated and measured bed level after $185 \mathrm{~min}$ for LSTF case T1C1

\section{T-head groin test T3C1}

The computations of waves, wave-induced currents, sediment transport, and morphological evolution for T3C1 were carried out in the same manner as for T1C1. Fig. 7 illustrates the comparison between the measurements and computations of significant wave height. As for T1C1, the wave conditions were well predicted by the Modified-EBED model. Note that measured wave data at ADV4 were not recorded because the wave gage at this location did not work properly.

Fig. 8 shows the detailed comparison between calculated and measured longshore current. In general, calculations obtained both with and without roller in the nearshore wave-induced current model were in quite good agreement with observations. With roller effects, the longshore current was slightly shifted towards the shoreline. The measurements of longshore current at ADV9 and ADV10 were not correct for this case (Gravens and Wang, 2009), thus they were not included in the comparison.

The calculations of the cross-shore current for T3C1 were also compared with the measurements (Fig. 9). As for T1C1, the calculated cross-shore current with roller was quite similar to that without roller, and both of them also underestimated the measured data. As for T1C1, an eddy was also created around ADV3 - ADV6 of the profiles Y20 and Y21, causing the calculated cross-shore current to have a shoreward direction. However, the measurements of the cross-shore current at profiles Y20 and Y21 were quite flat. Thus, there were discrepancies between calculations and measurements.

Fig. 10 shows the comparison between the calculated and measured bed level after 180 min for T3C1. As for T1C1, the beach evolution in the vicinity of the T-head groin was in good agreement 
with measurement. The sand accumulations in the lee of the T-head groin were well reproduced, although the beach erosion at downstream was not obtained in the calculations.
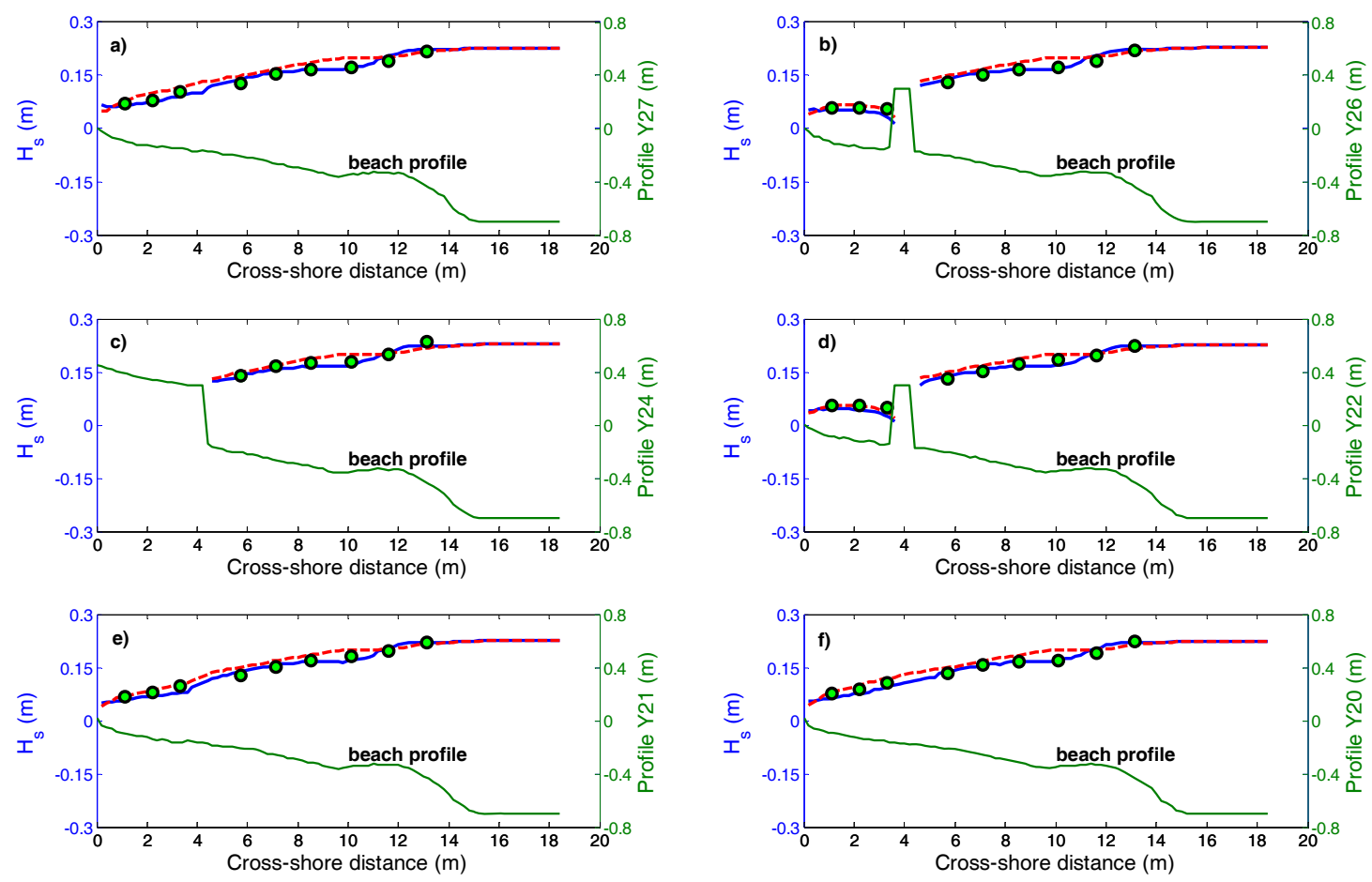

- Modified-EBED ---- EBED 0 Measured

Fig. 7. Comparison between measured and calculated significant wave height for LSTF case T3C1
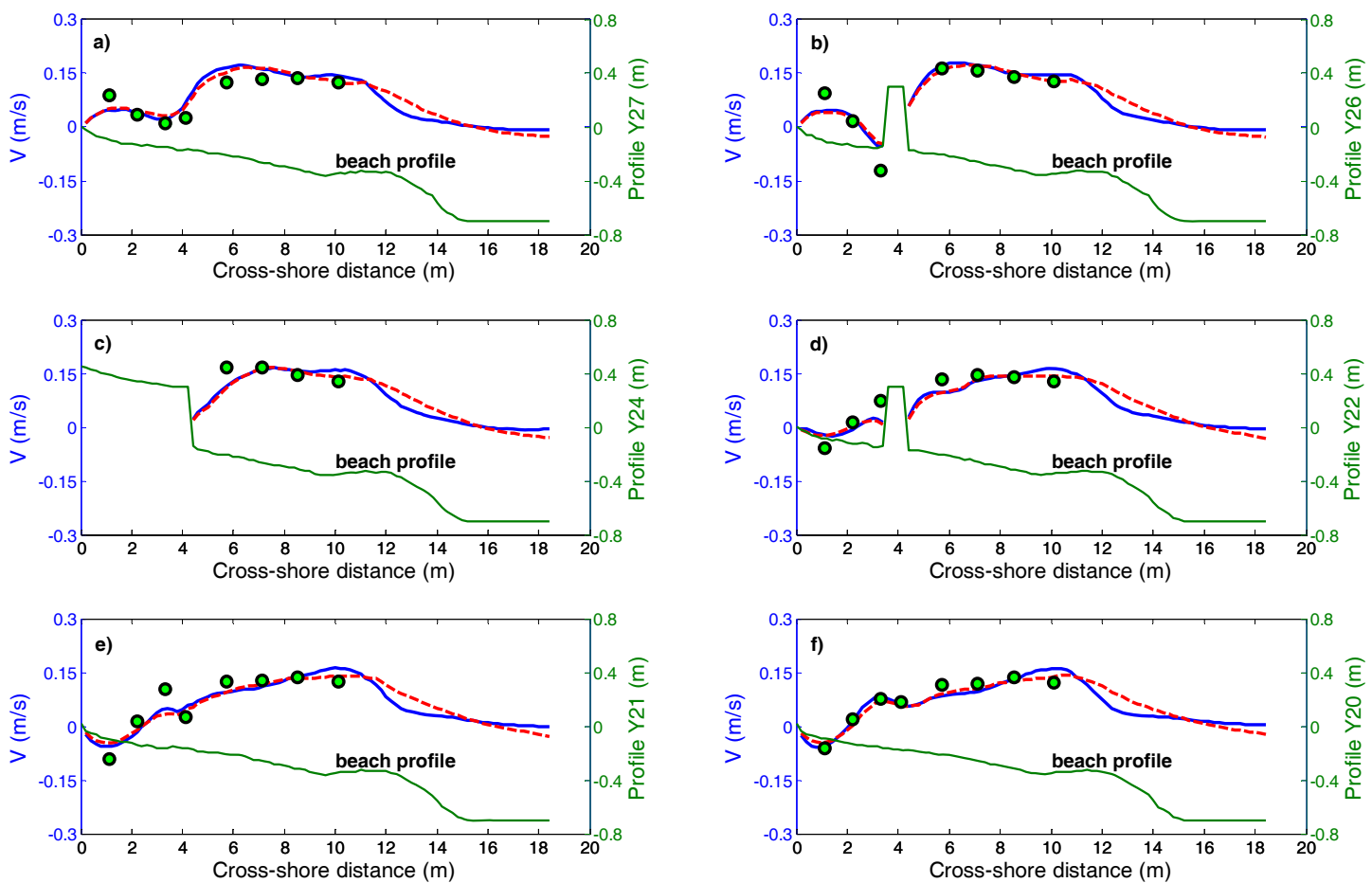

- With roller 2D ---- Without roller $\quad \circ$ Measured

Fig. 8. Comparison between measured and calculated longshore current for LSTF case T3C1 

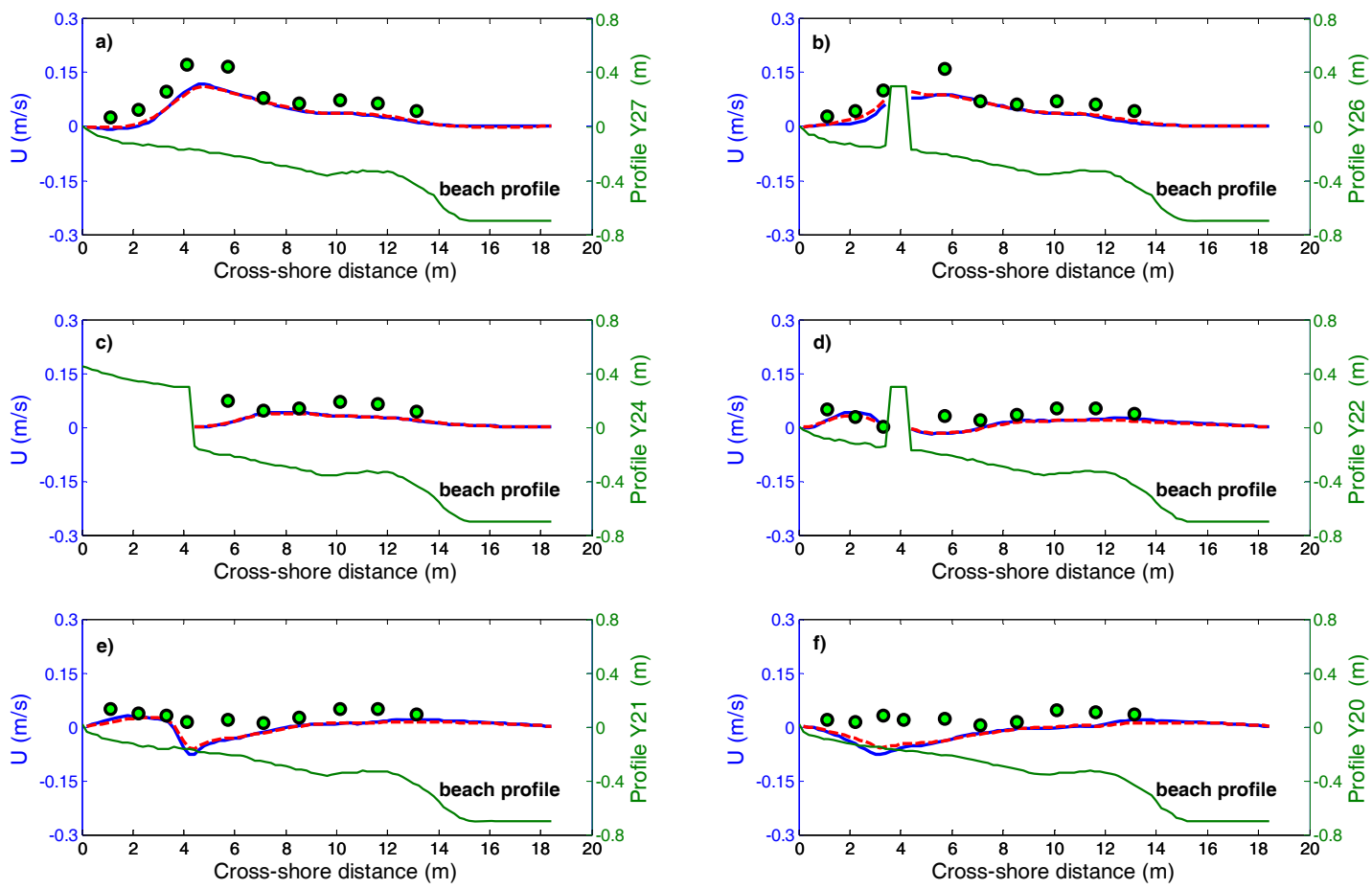

- With roller 2D ----- Without roller 0 Measured

Fig. 9. Comparison between measured and calculated cross-shore current for LSTF case T3C1

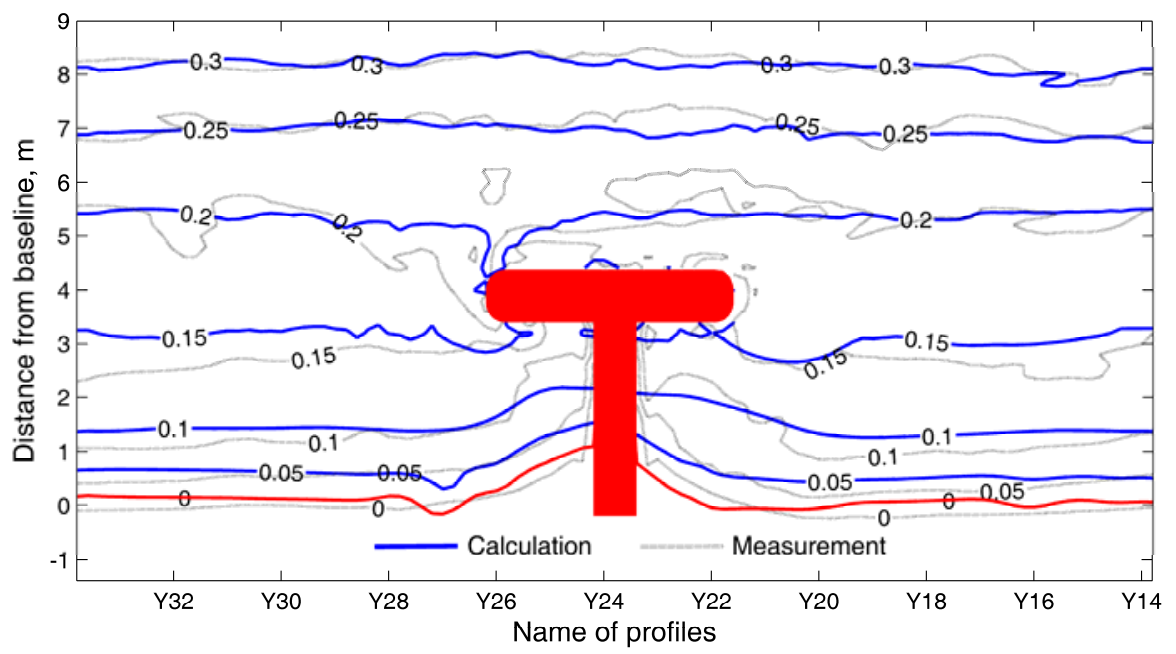

Fig. 10. Comparison between calculated and measured bed level after $180 \mathrm{~min}$ for LSTF case T3C1

\section{CONCLUSIONS}

The model development reported here built on the achievements from previous studies (Nam et al., 2009; Nam and Larson, 2009 and 2010). A unified model for beach evolution due to waves and currents was developed. It includes five sub-models: nearshore wave transformation, surface roller, nearshore wave-induced currents, sediment transport, and morphological evolution. The model was validated against two high-quality data sets from the LSTF basin, including one test case with a detached breakwater and one with a T-head groin. The simulations showed that the model could reproduce wave conditions in the surf zone in good agreement with measurements. Reasonable nearshore wave-induced currents were also obtained by the numerical model, although the cross-shore 
current was somewhat underestimated compared with measurements. The beach evolution in the vicinity of the detached breakwater and the T-head groin agreed fairly well with the measurements.

\section{ACKNOWLEDGMENTS}

This work was partly funded by Sida/SAREC in the framework of the Project VS/RDE/03 "The evolution and sustainable management in the coastal areas of Vietnam”, partly by the Lars Erik Lundberg Scholarship Foundation, partly by J. Gust. Richert Foundation, partly by ÅForsk (P. T. Nam), and partly funded under the Regional Sediment Management Program and under the Inlet Geomorphologic Work Unit of the Coastal Inlets Research Program of the U.S. Army Engineer Research and Development Center (M. Larson and H. Hanson). Dr. Hajime Mase at Kyoto University kindly provided the source code for the EBED model. Dr. Ping Wang at University of South Florida and Mr. Mark Gravens at CHL provided the experimental data from LSTF, which is greatly appreciated. The authors would also like to thank Dr. Nguyen Manh Hung and the late Prof. Pham Van Ninh for their great contributions to the Project VS/RDE/03. Permission was granted by Headquarters, U.S. Army Corps of Engineers, to publish this information.

\section{REFERENCES}

Camenen, B., and Larson, M. 2005. A general formula for non-cohesive bed load sediment transport. Estuarine, Coastal and Shelf Science 63, 249-260.

Camenen, B., and Larson, M. 2007. A unified sediment transport formulation for coastal inlet application. Technical report ERDC/CHL CR-07-1, US Army Engineer Research and Development Center, Vicksburg, MS.

Dally, W. R., and Brown, C. A. 1995. A modeling investigation of the breaking wave roller with application to cross-shore currents. J. Geophys. Res., 100(C12), 24873 - 24883.

Dally, W. R., Dean, R. G., and Dalrymple, R. A. 1985. Wave height variation across beaches of arbitrary profile. J. Geophys. Res., 90(C6), 11917 - 11927.

Elder, J. W. 1959. The dispersion of marked fluid in turbulence shear flow. Journal of Fluid Mechanics 5, 544-560.

Falconer, R. A. 1980. Modelling of planform influence on circulation in Harbors. Proc., 17th Int. Conf. on Coastal Engineering, ASCE, Sydney, 2726 - 2744.

Goda, Y. 2006. Examination of the influence of several factors on longshore current computation with random waves. Coastal Engineering, 53, 157-170.

Gravens, M.B., and Wang, P. 2009. Personal communication.

Gravens, M.B., and Wang, P. 2007. Data report: Laboratory testing of longshore sand transport by waves and currents; morphology change behind headland structures. Technical Report, ERDC/CHL TR-07-8, Coastal and Hydraulics Laboratory, US Army Engineer Research and Development Center, Vicksburg, MS.

Gravens, M.B., Wang, P., Kraus, N.C., and Hanson, H. 2006. Physical model investigation of morphology development at headland structures. Proc., 30th Int. Conf. on Coastal Eng., ASCE, San Diego, 3617-3629.

Johnson, H.K. 2004. Coastal area morphological modelling in the vicinity of groins. Proc., $29^{\text {th }}$ International Conf. on Coastal Engineering, ASCE, pp. 2646-2658.

Kraus, N. C., and Larson, M. 1991. NMLONG: Numerical model for simulating the longshore current; Report 1: Model development and tests. Technical Report DRP-91-1, U.S. Army Engineer Waterways Experiment Station, Vicksburg, MS.

Larson, M., and Kraus, N.C. 2002. NMLONG: Numerical model for simulating longshore current; Report 2: Wave-current interaction, roller modeling, and validation of model enhancements. Technical Report ERDC/CHL TR-02-22, US Army Engineer Research and Development Center, Vicksburg, MS.

Larson, M., and Wamsley, T.V. 2007. A formula for longshore sediment transport in the swash. Proc. Coastal Sediment'07, ASCE, pp. 1924-1937.

Leont'yev, I.O. 1999. Modelling of morphological changes due to coastal structures. Coastal Engineering 38, 143-166.

Mase, H. 2001. Multi-directional random wave transformation model based on energy balance equation. Coastal Engineering Journal, 43(4), 317 - 337.

Militello, A., Reed, C.W., Zundel, A.K., and Kraus, N.C. 2004. Two-dimensional depth-averaged circulation model M2D: version 2.0, Report 1, Technical document and User's Guide. Technical 
Report ERDC/CHL TR-04-2, US Army Engineer Research and Development Center, Vicksburg, MS.

Nam, P.T., Larson, M., Hanson, H., and Hoan, L.X. 2009. A numerical model of nearshore waves, currents, and sediment transport. Coastal Engineering 56, 1084-1096.

Nam, P.T., and Larson, M. 2009. A model of wave and current fields around coastal structures. Proc. Coastal Dynamics 2009, World Scientific Press, ISBN-13-978-981-4282-46-8 (with CD-ROM)

Nam, P.T., and Larson, M. 2010. Model of nearshore waves and wave-induced currents around a detached breakwater. Journal of Waterway, Port, Coastal and Ocean Engineering 136(3), 156176.

Nicholson, J., Broker, I., Roelvink, J.A., Price, D., Tanguy, J.M., and Moreno, L. 1997. Intercomparison of coastal area morphodynamic models. Coastal Engineering 31, 97-123.

Nishimura, H. 1988. Computation of neasrshore current. Nearshore Dynamics and Coastal Processes, Horikawa, K. (Ed), University of Tokyo Press, Tokyo, Japan, $271-291$.

Reid, R.O., and Bodine, B.R. 1968. Numerical model for storm surges in Galveston Bay. Journal of Waterways and Harbors Division 94 (WWI), 33-57.

Saied, U.M., and Tsanis, I.K. 2005. ICEM: Integrated Coastal Engineering Model. Journal of Coastal Research 21(6), 1275-1268.

Zyserman, J.A., and Johnson, H.K. 2002. Modelling morphological processes in the vicinity of shoreparallel breakwaters. Coastal Engineering 45, 261-284. 